\title{
Integrated Optimization of Battery Sizing, Charging, and Power Management in Plug-in Hybrid Electric Vehicles
}

\author{
Xiaosong Hu, Scott J. Moura, Nikolce Murgovski, Bo Egardt, Dongpu Cao
}

\begin{abstract}
This brief presents an integrated optimization framework for battery sizing, charging, and on-road power management in plug-in hybrid electric vehicles (PHEVs). This framework utilizes convex programming (CP) to assess interactions between the three optimal design/control tasks. The objective is to minimize carbon dioxide $\left(\mathrm{CO}_{2}\right)$ emissions, from the on-board internal combustion engine and grid generation plants providing electrical recharge power. The impacts of varying daily grid $\mathrm{CO}_{2}$ trajectories on both the optimal battery size and charging/power management algorithms are analyzed. We find that the level of grid $\mathrm{CO}_{2}$ emissions can significantly impact the nature of emissions-optimal on-road power management. We also find that the on-road power management is the most important design task for minimizing emissions, through a variety of comparative studies.

Index Terms-Component Sizing, Charging Control, Energy Management, Convex Optimization, Plug-in Hybrid Electric Vehicle, Sustainable Transportation.
\end{abstract}

\section{INTRODUCTION}

Plug-in hybrid electric vehicles (PHEVs) potentially reduce fossil fuel dependence while enabling synergies between vehicles and the electric grid [1], [2]. The performance, economics, and environmental benefits of PHEVs are, however, considerably influenced by their charging patterns, power management strategies, and energy storage system sizes. These three aspects are typically considered in isolation, as discussed next.

Researchers have examined PHEV charging schedule designs for objectives such as load following/stabilization [3], enhanced grid network efficiency [4], and battery health [5]. These dynamically updated charging schedules may use realtime information on electricity price, green house gas (GHG) emissions, and so forth. Many optimization methodologies have been employed for this problem, such as convex programming (CP) [6], dynamic programming (DP) [7], linear programming (LP) [8], and game theory (GT) [9].

In parallel, researchers have examined on-road power management strategies that can be organized into two categories:

$\mathrm{X} . \mathrm{Hu}$ is with the National Active Distribution Network Technology Research Center, Beijing Jiaotong University, Beijing 100044, China, and with Energy, Controls, and Applications Laboratory, University of California, Berkeley, CA 94720, USA. (e-mail: xiaosonghu@ieee.org).

S. J. Moura is with Energy, Controls, and Applications Laboratory, University of California, Berkeley, CA 94720, USA. (e-mail: smoura@berkeley.edu).

N. Murgovski, and B. Egardt are with the Department of Signals and Systems, Chalmers University of Technology, Gothenburg 41296, Sweden. (e-mails: nikolce.murgovski@chalmers.se; bo.egardt@chalmers.se).

D. Cao is with the Center for Automotive Engineering, Cranfield University, Bedford MK 43 0AL, UK. (e-mail: d.cao@cranfield.ac.uk). charge depleting-charge sustaining (CD-CS) and blended approaches [10]. In the CD-CS strategy, PHEVs first operate in a pure electric mode until a minimum battery State-of-Charge (SOC) threshold is reached. Then the controller switches to a charge sustenance mode. In the blended strategy, an optimal control problem is typically solved, which results in simultaneous operation of the on-board power sources over time. Various optimization approaches have been studied to generate optimal power split algorithms for HEVs/PHEVs, such as DP [10], instantaneous optimization (e.g., Equivalent Consumption Minimization Strategy (ECMS) [11], [12], Pontryagins Minimum Principle (PMP) [13], [14]), model predictive control (MPC) [15], [16], and CP [17].

All the foregoing studies focus on either charging control or on-road power management. These two aspects, however, are strongly coupled [18]. To fully investigate interactions between the two optimal control problems, a simultaneous optimization framework is needed. DP has been used to implement such a framework, where global optimality is achieved at the cost of tremendous computational complexity [19]. Other studies perform the on-road power management and charging schedule optimization sequentially [20]. Battery size also substantially impacts the economic and environmental advantages of PHEVs. Most of previous work evaluated combined on-road power management and component sizing optimization in a bi-loop manner (the outer loop is for sizing, and the inner loop for power management)[21], [22]. Diverse heuristic optimization algorithms were used for the outer-loop sizing optimization with heavy computational burden, such as particle swarm optimization (PSO) [23] and DIRECT [24]. To increase computational efficiency, simultaneous power management and sizing optimization was also reported, e.g., CP [17]. A survey of optimal design strategies for HEVs/PHEVs is given in [25].

The tradeoffs between battery sizing, charging control, and the power management strategy remain insufficiently examined and merit further exploration. For example, what is the optimal battery size to minimize PHEV GHG emissions? How do dynamic grid emission profiles impact battery size, charging schedule, and power management strategy?

This brief extends our previous work on combined PHEV battery sizing/power management optimization [17] by incorporating charging schedule optimization to minimize the total amount of daily $\mathrm{CO}_{2}$ emissions. Its overarching goal is to enable a systematic evaluation of the interplay between the 
three optimal design/control problems. Two key contributions are added to the related literature. First, a CP framework is formulated to enable rapid, globally optimal solutions. The optimal battery size, charging patterns, and power management strategy in a 24-hour horizon can be efficiently extracted in seconds. This facilitates online updates of the control strategies, given appropriate forecast information. Second, the impact of variable daily grid $\mathrm{CO}_{2}$ profiles on the optimal design/control is analyzed. The optimality loss of the optimized solution at a medium $\mathrm{CO}_{2}$ level is quantified when applied to different $\mathrm{CO}_{2}$ levels.

The remainder of the brief is arranged as follows. Section II details the modeling of a PHEV propulsion system and briefly introduces a grid emissions model. The $\mathrm{CP}$ framework is described in Section III. The optimization results are discussed in Section IV followed by conclusions presented in Section V.

\section{PHEV AND GRID EMISSION MOdels}

We consider a series plug-in hybrid electric powertrain architecture shown in Fig. 1. In the following subsections, we detail a convex model formulation of this drivetrain and grid $\mathrm{CO}_{2}$ emissions. Then we formulate the optimization program, which takes the form of the canonical nonlinear programming problem,

$$
\begin{array}{rl}
\min _{x} & f(x) \\
\text { subject to } & g(x) \leq 0, \\
& h(x)=0 .
\end{array}
$$

A convex program is the special case where $f(x)$ is convex, $g(x)$ is convex, and $h(x)$ is affine with respect to the optimization variable $x$, over the feasible set [26]. Consequently, the model equations and constraints are derived to satisfy these properties. As will become evident in the model formulation, the optimization variables are $P_{b, k}, P_{b t, k}, E_{b, k}, n, P_{e g u, k}, T_{k}$, which represent the electrochemical battery power, electrical battery power, battery energy, number of cells, enginegenerator unit (EGU) power, and electric motor (EM) torque, respectively. Note that $n$ is a design variable, and the remaining optimization variables are controls. Therefore, we formulate a combined design/control optimization problem as a convex programming problem such that both design and controls can be simultaneously solved. This is different from DP and PMP where only controls are solved sequentially in time. To consider design optimization, an outer loop is required. A contrast between $\mathrm{CP}$ and bi-loop scenario is sketched in Fig. 2. Symbol $k \in\{0, \cdots, N\}$ indexes discrete time, and is herein dropped to reduce notational clutter, except to emphasize dynamics. We consider a $\Delta t_{d}=1 \mathrm{sec}$. time step when the vehicle is driving $t_{d} \in M_{d}$, and $\Delta t_{c}=1 \mathrm{~min}$ when it is charging $t_{c} \in M_{c}$. Here, $M_{d}$ and $M_{c}$ are the sets of discrete time steps for driving and charging, respectively.

\section{A. PHEV Model}

The PHEV consists of a lithium-ion battery pack, $35 \mathrm{~kW}$ permanent-magnet synchronous electric motor (EM), and an

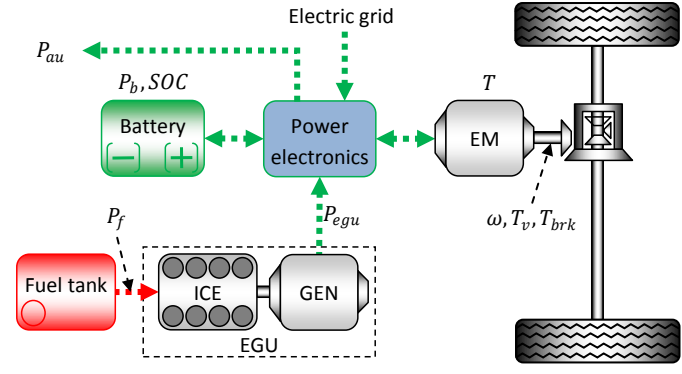

Fig. 1. Plug-in hybrid propulsion system.
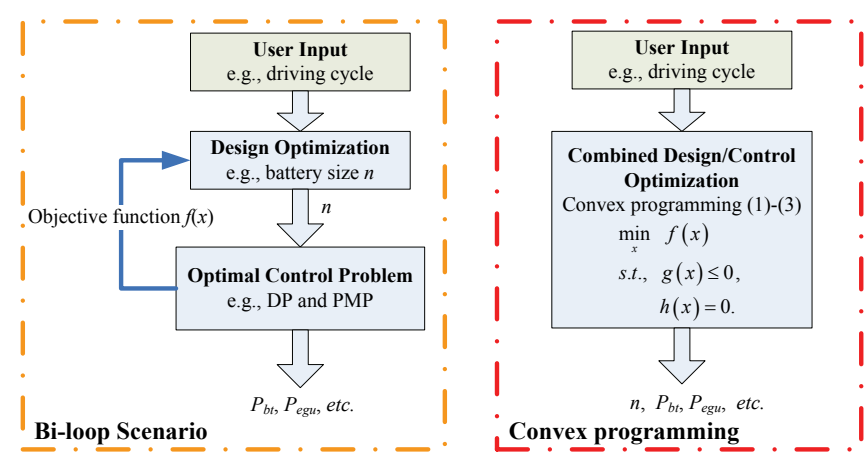

Fig. 2. Contrast between convex programming and bi-loop scenario for the combined design/control optimization in PHEVs.

engine-generator unit (EGU) with a power rating of $35 \mathrm{~kW}$. Convex modeling formulations of these components are provided next.

1) Battery Pack: The lithium-ion battery pack comprises strings connected in parallel. Each battery cell is modeled as an open circuit voltage $(\mathrm{OCV}), U(s o c)$, in series with a resistor, $R$, and the power at the terminals is given by

$$
P_{b t}=P_{b}-n R i^{2},
$$

where $P_{b}=n U(s o c) i$, and $i$ is the cell current. The discharge power is positive and charge power is negative. An affine approximation of the OCV function given by

$$
U(s o c)=\frac{Q}{C} s o c+U_{0},
$$

is employed [27], where $Q$ and $C$ have the interpretation of charge capacity and capacitance (their values are listed in Table II). This affine approximation is determined by fitting experimental $\mathrm{LiFePO}_{4}$ cell data and is reasonably accurate within the 20\%-80\% SOC window. One may express the battery pack energy as

$$
\begin{aligned}
E_{b} & =n Q \int_{0}^{s o c} U(\sigma) d \sigma=n Q \int_{0}^{s o c}\left[\frac{Q}{C} \sigma+U_{0}\right] d \sigma \\
& =n Q\left[\frac{Q}{2 C} s o c^{2}+U_{0} s o c\right]=\frac{n C}{2}\left[U^{2}(s o c)-U_{0}^{2}\right] .
\end{aligned}
$$

By solving for $U(s o c)$ as a function of $E_{b}$ in (6) and plugging this expression into the electrochemical pack power $P_{b}$, we 
attain $i$ as a function of $P_{b}$ and $E_{b}$, which is ultimately substituted into (4), yielding equality constraint

$$
P_{b t}-P_{b}+\frac{R C P_{b}^{2}}{2 E_{b}+U_{0}^{2} C n}=0 .
$$

Using the properties of convex functions ( $\$ 3.2[26])$, it is easy to verify the left-hand side of (7) is convex w.r.t. $P_{b t}, P_{b}, E_{b}, n$ for non-negative $E_{b}, n$. When dimensioning the battery pack, the optimal energy capacity is assumed to take non-quantized values, which is fulfilled by relaxing $n$ to a continuously valued variable. We assume battery cells can be fabricated in accordance with the optimized pack power and energy [27]. The convex battery model constraints representing parked charging and propulsion during driving are given by

$$
\begin{aligned}
E_{b, k+1} & =E_{b, k}-\Delta t \cdot P_{b, k}, \\
P_{b t} & -P_{b}+\frac{R C P_{b}^{2}}{2 E_{b}+U_{0}^{2} C n} \leq 0, \\
n E_{\text {cell,min }} & \leq E_{b} \leq n E_{\text {cell,max }}, \\
n & \geq 0,
\end{aligned}
$$

where $E_{\text {cell,min }}$ and $E_{\text {cell, max }}$ represent the $\min /$ max allowable cell energy levels. Equation (8) encodes the battery energy storage dynamics and clearly produces an affine equality constraint w.r.t. all optimization variables [27]. Inequality (9) is a relaxed form of equality constraint (7), and is necessary to preserve convexity. One can analytically show this constraint is active at the optimal solution [27], thus incurring zero error. The battery energy limits (10) also produce convex inequality constraints (as proved in Lemma 1 and Remark 1 ), and the number of cells (11) must be nonnegative. In addition, the battery cell current is limited during both driving and recharging [19]. Consequently, battery power constraints are formulated for the driving and charging modes as

$$
\left\{\begin{array}{rr}
i_{\min } \sqrt{n\left(\frac{2}{C} E_{b, k}+U_{0}^{2} n\right)} \leq P_{b, k} \leq i_{\max } \sqrt{n\left(\frac{2}{C} E_{b, k}+U_{0}^{2} n\right),} & \text { for } k \in M_{d}, \\
P_{b t, \min } \leq P_{b t, k} \leq 0, & \text { for } k \in M_{c},
\end{array}\right.
$$

where $i_{\min }, i_{\max }$ are the cell current limits for power management during driving, and $P_{b t \text {,min }}$ is the charging power limit while parked. Again, (12) produces convex inequality constraint functions with respect to $P_{b}, n, E_{b}$, as proved in Lemma 1 and Remark 1.

Lemma 1 ( $\S 3.1[26])$ : The inequality constraint $H(x) \leq 0$ is convex if and only if the domain of $H(x)$ is a convex set, and its Hessian $\nabla^{2} H(x)$ is positive semidefinite.

Remark 1: For $n E_{\text {cell,min }}-E_{b}$ and $E_{b}-n E_{\text {cell,max }}$, Lemma 1 clearly holds, and thus the convexity of (10) is guaranteed. Similarly, Lemma 1 clearly holds for the battery power constraints during charging. According to Lemma 1, $\sqrt{n\left(\frac{2}{C} E_{b, k}+U_{0}^{2} n\right)}$ is concave with respect to $n$ and $E_{b}$. Since $i_{\min }<0$ and $i_{\max }>0, i_{\min } \sqrt{n\left(\frac{2}{C} E_{b, k}+U_{0}^{2} n\right)}$ and $-i_{\max } \sqrt{n\left(\frac{2}{C} E_{b, k}+U_{0}^{2} n\right)}$ are convex (as per basic operations

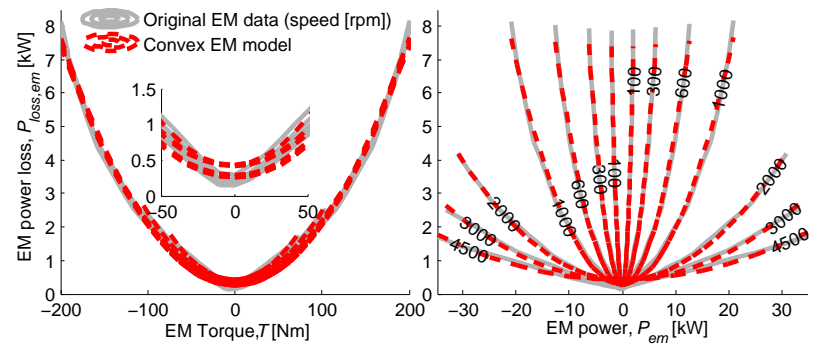

Fig. 3. Original EM power data and approximate model with power loss as a quadratic function of torque.

preserving convexity of functions (§3.2 [26])). Eventually, Lemma 1 holds for (12), and its convexity is thereby satisfied.

As in [19], we enforce net zero energy transfer over the 24 hour period, so that today's optimal control does not sacrifice performance tomorrow by depleting the battery,

$$
E_{b, 0}=E_{b, N}
$$

where $k=0$ and $k=N$ represent the initial and final time steps of the 24-hour PHEV operation.

2) Electric Motor (EM): The electrical power balance equation during driving is given by

$$
P_{e m}+P_{l o s s, e m}+P_{a u}=P_{b t}+P_{e g u}
$$

where $P_{e m}$ is the EM power, $P_{l o s s, e m}$ denotes parasitic losses in the EM, and $P_{a u}$ represents vehicle auxiliary loads (e.g. HVAC). The required EM power depends on the drive cycle velocity and vehicle mass (i.e. battery size) according to

$$
P_{e m}=T \omega \geq T_{v} \omega=(A(\omega) n+B(\omega)) \omega
$$

where $T_{v}$ is the torque demand on the shaft between the EM and the final drive, which is an affine function of the battery size $n$, as detailed in the Appendix. Symbol $\omega$ is the EM angular shaft speed and is proportional to wheel speed. EM torque may be less than the required torque for deceleration, since the difference can be provided by frictional brake torque. The EM losses $P_{\text {loss,em }}$ are modeled by a convex quadratic function of EM torque $T$,

$$
P_{\text {loss }, e m}=a_{2}(\omega) T^{2}+a_{1}(\omega) T+a_{0}(\omega),
$$

where $a_{2}, a_{1}, a_{0}$ are coefficients that depend on $\omega$. Note $a_{2}(\omega) \geq 0$ uniformly in $\omega$ to preserve convexity. EM power loss data and the convex regression are shown in Fig. 3. Additionally, the EM torque is limited by angular speed dependent bounds given by

$$
T_{\min }(\omega) \leq T \leq T_{\max }(\omega) .
$$

3) Engine-Generator Unit (EGU): The rate of gasoline energy consumption, i.e., "gasoline power" $P_{f}$, along the EGU optimal operating line (OOL) is described by

$$
P_{f}=b_{2} P_{e g u}^{2}+b_{1} P_{e g u}+b_{0}
$$

where $b_{2} \geq 0$ to preserve convexity. The regression fit is displayed in Fig. 4. The EGU power $P_{e g u}$ is also bounded by limits

$$
0 \leq P_{\text {egu }} \leq P_{\max , e g u} .
$$



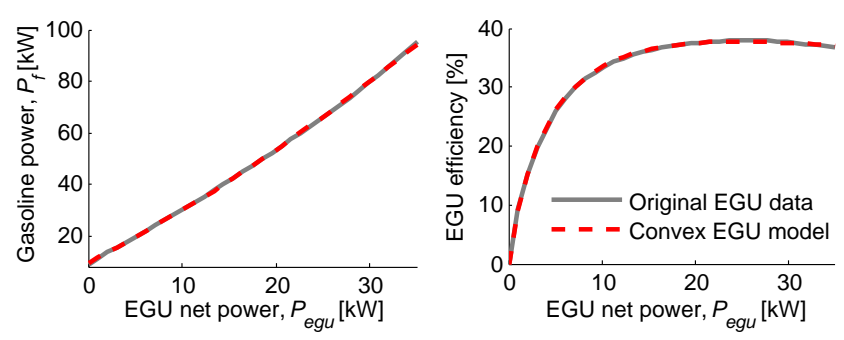

Fig. 4. Original gasoline consumption data and approximate model with power loss as a quadratic function of EGU net power.

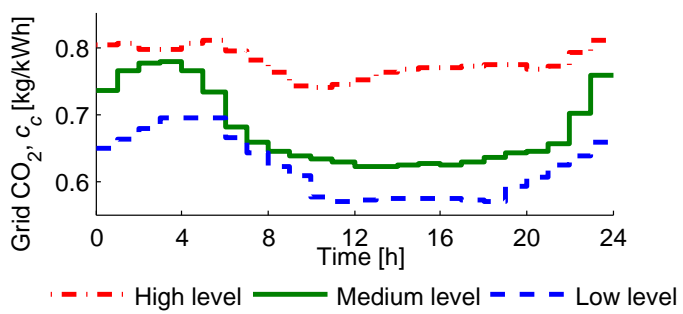

Fig. 5. Grid $\mathrm{CO}_{2}$ emission trajectories, i.e, $c_{c, k}$ in (23) for optimization (data is taken from [28]).

Finally, a heuristic engine on/off control signal is determined by a threshold policy

$$
e= \begin{cases}1, & \text { for } T_{v} \omega \geq P_{o n}^{*} \\ 0, & \text { otherwise }\end{cases}
$$

That is, the engine shuts off when vehicle power demand is smaller than a threshold $P_{o n}^{*}$. The best threshold value $P_{o n}^{*}$ is achieved by iteratively solving the convex optimization problem ((24)-(26) in Section III), over different $P_{o n}^{*}$ values in an outer loop. We observe from simulations that this heuristic could give a solution close to the global optimum from DP (see Table III).

\section{B. Grid $\mathrm{CO}_{2}$ Model}

We adopt an economic grid dispatch model for power plants in Michigan [28] to generate marginal grid $\mathrm{CO}_{2}$ emissions associated with PHEV charging. This provides the appropriate coefficients for the objective function, to be defined in Section III. Given a total load demand, the model performs grid dispatch and calculates generation costs and $\mathrm{CO}_{2}$ emissions. The resultant $\mathrm{CO}_{2}$ emissions per unit energy are within a range from 0.55 to $0.85[\mathrm{~kg} / \mathrm{kWh}$, which is independent of the grid load (the inclusion of PHEVs). The reason is that the underlying power plants are assumed to remain the same, inducing the same range of average $\mathrm{CO}_{2}$. Three 24-hour $\mathrm{CO}_{2}$ traces reflecting days of high, medium, and low $\mathrm{CO}_{2}$ emissions caused by different generation mixes (see Fig. 5) are chosen for the subsequent integrated optimization problem (Section III). More details on the grid model are given in [19], [28].

\section{INTEGRATED OPTIMIZATION FRAMEWORK}

We consider daily PHEV operation composed of two identical driving trips (at 8 a.m. and at 5 p.m.) and parking, which

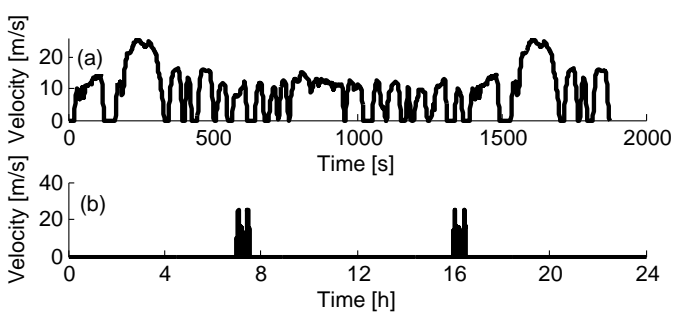

Fig. 6. FTP-75 driving cycle and timing of the daily PHEV operation: (a) FTP-75 cycle; (b) Timing of the 24-hour PHEV usage.

is representative of workday commutes. The Federal Test Procedure (FTP-75) is chosen to simulate city driving patterns. The FTP-75 driving cycle and commute times over 24-hour operation are indicated in Fig. 6. Although specific routes from Fig. 6 are employed here, the integrated optimization framework is equally applicable to other velocity profiles, trip lengths, and commute times. The impact of trip profiles and traffic conditions on PHEV energy consumption is elaborated in [29], [30].

The objective function $F$ is formulated to minimize the total amount of daily $\mathrm{CO}_{2}$ emissions associated with gasoline consumption and recharging the PHEV from the grid.

$$
\text { where } \begin{aligned}
F & =F_{\text {gas }}+F_{\text {grid }}, \\
F_{\text {gas }} & =\frac{c_{g} \Delta t_{d}}{L_{g} \rho_{g}} \sum_{k \in M_{d}} P_{f}\left(P_{\text {egu }, k}\right), \\
F_{\text {grid }} & =\frac{\Delta t_{c}}{\eta_{c}} \sum_{k \in M_{c}} c_{c, k} P_{b t, k},
\end{aligned}
$$

where $c_{g}$ is the $\mathrm{CO}_{2}$ produced by combusting gasoline in $[\mathrm{kg} / \mathrm{L}], L_{g}$ is the lower heating value of gasoline in $[\mathrm{J} / \mathrm{g}]$, and $\rho_{g}$ is the gasoline density in $[\mathrm{g} / \mathrm{L}]$. The time-varying grid $\mathrm{CO}_{2}$ in $[\mathrm{kg} / \mathrm{kWh}]$ is represented by $c_{c, k}$, and $\eta_{c}$ denotes average charger efficiency.

The optimization variables are $P_{b, k}, P_{b t, k}, E_{b, k}, n, P_{e g u, k}$, $T_{k}$, where $k \in M_{d} \cup M_{c}$ indexes time. The time indices are grouped into the set of driving time $M_{d}$ and charging time $M_{c}$ index sets. Consequently, we summarize the optimization problem as

$$
\begin{array}{cl}
\min _{P_{b}, P_{b t}, E_{b}, n, P_{\text {egu }}, T} & F=F_{\text {gas }}+F_{\text {grid }} \\
\text { subject to: } \quad & (8)-(13),(15)-(20), \\
& P_{\text {em }}+P_{\text {loss }, \text { em }}+P_{a u} \leq P_{b t}+P_{\text {egu }} .
\end{array}
$$

Since convex equality constraints (14), (16) do not produce convex feasible sets, we relax this equality to an inequality in (26). One can analytically show this constraint is active at the optimal solution, uniformly in time [27]. Additionally, we remark that it is possible to eliminate optimization variables via the equality constraints. This, however, destroys the convex structure that we desire. The tradeoff is added dimensions to the decision space. This is worthwhile, however, due to the efficiency of numerical $\mathrm{CP}$ solvers relative to general purpose nonlinear programming algorithms [27]. Finally, we note that 
the objective function (24) is not explicitly dependent on all optimization variables. However, all variables are coupled via constraints.

The CVX solver [26], is applied to parse the problem, yielding a general semi-definite program (SDP) that can be efficiently solved by SeDuMi [31]. Theoretical and algorithmic details of convex programming are discussed in [26]. The key parameters of the small-size PHEV are listed in Table I, while the main specifications of the on-board power sources are given in Table II. The additional mass resulting from packaging and circuitry is assumed to account for $12.3 \%$ of the total mass of the battery pack [27].

\section{Results \& Discussion}

The optimal trajectories under a high grid $\mathrm{CO}_{2}$ scenario are showcased in Fig. 7. The PHEV effectively operates in charge-sustaining mode during the two trips, and there is no use of electrical grid energy (i.e. the PHEV operates as a series HEV). As demonstrated in Fig. 8, the EGU operates near the maximum efficiency point such that gasoline usage is less carbon intensive per unit power. The optimal trajectory under the low $\mathrm{CO}_{2}$ level is shown in Fig. 9. In this case, the PHEV exerts pure electric mode for driving and recharges when grid $\mathrm{CO}_{2}$ is lowest. Reduced grid $\mathrm{CO}_{2}$ relative to engine $\mathrm{CO}_{2}$ discourages gasoline consumption. The result under the medium $\mathrm{CO}_{2}$ level is similar to the case of the low $\mathrm{CO}_{2}$ level.

The optimized battery sizes, $\mathrm{CO}_{2}$ emissions, and computational times under the three grid $\mathrm{CO}_{2}$ levels are summarized in Table III, where DP results are also provided for benchmarking purposes. Given the same battery size optimized by $\mathrm{CP}$, DP guarantees the globally optimal charging and power management strategy and incorporates binary engine on/off control. The CP and DP results are comparable. In particular, the greatest loss of optimality is $0.6 \%$ under the high grid $\mathrm{CO}_{2}$ case, which is attributed to the convex modeling assumptions and sub-optimal engine-off control designed in Section II. Due to pure electric-mode driving under both the medium and low grid $\mathrm{CO}_{2}$ levels, the associated losses are about $0.3 \%$. $\mathrm{CP}$ requires 2-3 orders of magnitude less computational time than DP. DP requires more than 2 hours to solve, even without including the battery sizing task.

Additionally, the optimal battery size does not necessarily increase, as $\mathrm{CO}_{2}$ levels decrease. In order to further explore the coupling between battery sizing and $\mathrm{CO}_{2}$ emissions, the optimization results with respect to different battery sizes TABLE I

Key Vehicle Parameters

\begin{tabular}{lcll}
\hline \hline Parameter & Value & Parameter & Value \\
\hline Frontal area $A_{f}\left[\mathrm{~m}^{2}\right]$ & 2.000 & $\begin{array}{l}\text { Vehicle mass excluding } \\
\text { battery pack } m_{v}[\mathrm{~kg}]\end{array}$ & 1155 \\
$\begin{array}{l}\text { Aerodynamic drag coef- } \\
\text { ficient } c_{d}\end{array}$ & 0.300 & EM inertia $I_{e m}\left[\mathrm{kgm}^{2}\right]$ & 0.100 \\
Air density $\rho\left[\mathrm{kg} / \mathrm{m}^{3}\right]$ & 1.184 & $\begin{array}{l}\text { Inertia of final drive and } \\
\text { wheels } I\left[\mathrm{kgm}^{2}\right]\end{array}$ & 1.086 \\
$\begin{array}{l}\text { Rolling resistance coef- } \\
\text { ficient } c_{r}\end{array}$ & 0.010 & $\begin{array}{l}\text { Vehicular auxiliary } \\
\text { power, } P_{a u}[\mathrm{~kW}]\end{array}$ & 0.800 \\
Wheel radius $r[\mathrm{~m}]$ & 0.308 & Final gear $\lambda$ & 4.000 \\
\hline \hline
\end{tabular}
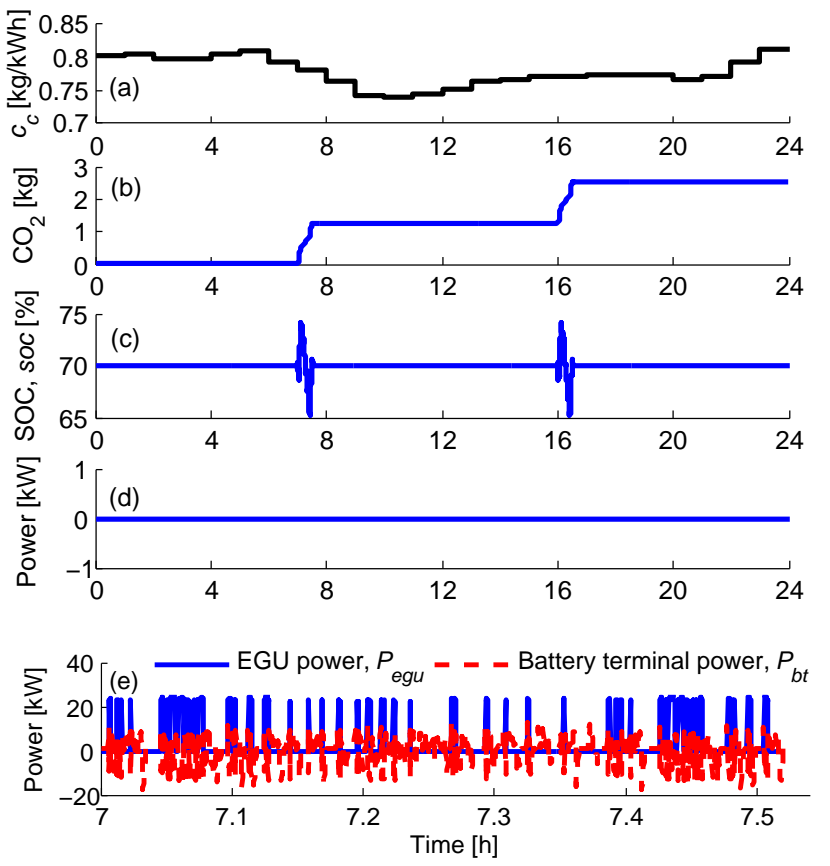

Fig. 7. Optimal trajectories under the high grid $\mathrm{CO}_{2}$ level: (a) $\mathrm{Grid}_{\mathrm{CO}_{2}}$; (b) Cumulative $\mathrm{CO}_{2}$; (c) SOC trajectory; (d) Recharging power; (e) power split in the first trip.

under the high grid $\mathrm{CO}_{2}$ case are exhibited in Fig. 10. The dependency of $\mathrm{CO}_{2}$ emissions on battery size is nonlinear. Furthermore, the globally optimal solution corresponds to high EGU efficiency. Enlarging the battery past a critical point will increase gasoline consumption and consequently $\mathrm{CO}_{2}$ emissions, since the PHEV mass increase outweighs the marginal improvement of the average EGU efficiency. The PHEV does not recharge in this case, for any battery size. The optimal battery sizing under the low grid $\mathrm{CO}_{2}$ case is depicted in Fig. 11. When the battery is less than $3 \mathrm{kWh}$, the PHEV blends battery and engine power, whereas the resultant $\mathrm{CO}_{2}$ emissions are not minimized with respect to battery size. On the other hand, overly large batteries lead to unnecessary electricity consumption as a consequence of increased mass.

Using the established optimization framework, different

TABLE II

MAIN SPECIFICATIONS OF THE ONBOARD POWER SOURCES

\begin{tabular}{|c|c|c|c|}
\hline$\overline{\text { Parameter }}$ & Value & Parameter & $\overline{\text { Value }}$ \\
\hline $\begin{array}{l}\text { Gasoline-related } \mathrm{CO}_{2} \\
c_{g}[\mathrm{~kg} / \mathrm{l}]\end{array}$ & 2.320 & $\begin{array}{l}\text { Maximum cell discharge } \\
\text { current } i_{\max }[\mathrm{A}]\end{array}$ & 70 \\
\hline $\begin{array}{l}\text { Gasoline lower heating } \\
\text { value } L_{g}[\mathrm{~J} / \mathrm{g}]\end{array}$ & 42600 & $\begin{array}{l}\text { Maximum cell charge } \\
\text { current, } i_{\min }[\mathrm{A}]\end{array}$ & -35 \\
\hline Gasoline density $\rho_{g}[\mathrm{~g} / \mathrm{l}]$ & 749 & $\begin{array}{l}\text { Initial cell SOC } s o c_{0} \\
{[\%]}\end{array}$ & 70 \\
\hline $\begin{array}{l}\text { Maximum EGU power } \\
P_{\max , \text { egu }}[\mathrm{W}]\end{array}$ & 35000 & $\begin{array}{l}\text { Maximum cell SOC } \\
s o c_{\max }[\%]\end{array}$ & 90 \\
\hline $\begin{array}{l}\text { Nominal cell capacity } Q \\
\text { [As] }\end{array}$ & 8280 & $\begin{array}{l}\text { Minimum cell SOC } \\
s o c_{\min }[\%]\end{array}$ & 30 \\
\hline $\begin{array}{l}\text { Cell equivalent capaci- } \\
\text { tance } C[\mathrm{~F}]\end{array}$ & 51782 & $\begin{array}{l}\text { Maximum pack recharg- } \\
\text { ing power } P_{b t, \min }[\mathrm{W}]\end{array}$ & -1000 \\
\hline Cell resistance $R$ [ohm] & 0.01 & $\begin{array}{l}\text { Average charger } \\
\text { efficiency } \eta_{c}[\%]\end{array}$ & 98 \\
\hline Cell mass $m_{b}[\mathrm{~kg}]$ & 0.07 & Nominal cell voltage $[\mathrm{V}]$ & 3.3 \\
\hline
\end{tabular}




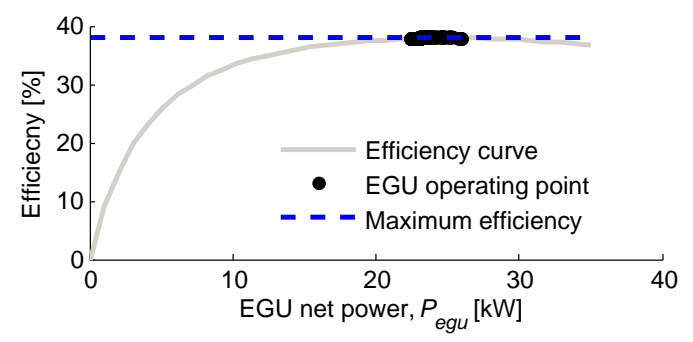

Fig. 8. EGU efficiency.
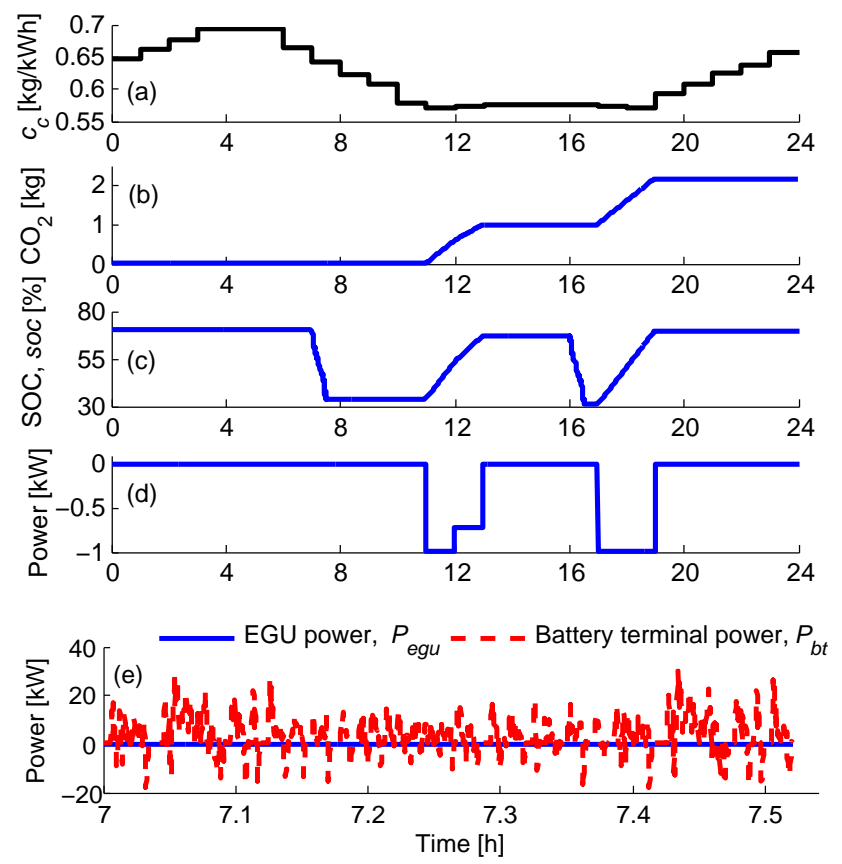

Fig. 9. Optimal trajectories under the low grid $\mathrm{CO}_{2}$ level: (a) $\mathrm{Grid}^{\mathrm{CO}_{2}}$; (b) Cumulative $\mathrm{CO}_{2}$; (c) SOC trajectory; (d) recharging power; (e) power split in the first trip.

charging/power management strategies can be conveniently assessed by changing the optimization constraints. For instance, a comparison is conducted between the optimal solution and three heuristic charging/power management strategies under the high grid $\mathrm{CO}_{2}$ level (see Fig. 12). In this case, note that optimizing on-road power management (i.e., high EGU efficiency) is critical to reducing $\mathrm{CO}_{2}$ emissions, while intuitive full charging before each trip is a non-optimal decision. Analogous analysis can be made for the medium and low $\mathrm{CO}_{2}$ levels.

In practice, one cannot optimize PHEV design \& control for varying daily grid $\mathrm{CO}_{2}$ traces. Namely, adjusting battery pack size is often difficult, particularly for traditional integrated battery pack designs. One alternative is to obtain the optimal solution under the medium grid $\mathrm{CO}_{2}$ trace, and then evaluate its performance on other traces. This approach, nevertheless, results in loss of optimality with respect to $\mathrm{CO}_{2}$ minimization, which is quantified in Fig. 13. The approach incurs about $14 \%$ $\mathrm{CO}_{2}$ increase in the case of high grid $\mathrm{CO}_{2}$ level. Since the $\mathrm{CP}$ framework enables rapid updates of charging/power manage-
TABLE III

OPTIMIZATION RESULTS UNDER VARIOUS GRID $\mathrm{CO}_{2}$ EMISSION SCENARIOS

\begin{tabular}{|c|c|c|c|c|}
\hline & & High & Medium & Low \\
\hline \multirow{2}{*}{$\mathrm{CO}_{2}$} & DP & $2.51 \mathrm{~kg}$ & $2.36 \mathrm{~kg}$ & $2.16 \mathrm{~kg}$ \\
\hline & $\mathrm{CP}$ & $2.53 \mathrm{~kg}$ & $2.37 \mathrm{~kg}$ & $2.17 \mathrm{~kg}$ \\
\hline \multirow{2}{*}{ Time* } & DP & $2.48 \mathrm{~h}$ & $2.32 \mathrm{~h}$ & $2.16 \mathrm{~h}$ \\
\hline & $\mathrm{CP}$ & $17.60 \mathrm{~s}$ & $13.91 \mathrm{~s}$ & $12.42 \mathrm{~s}$ \\
\hline Battery size & CP \& DP & $3.78 \mathrm{kWh}$ & $5.17 \mathrm{kWh}$ & $5.07 \mathrm{kWh}$ \\
\hline
\end{tabular}
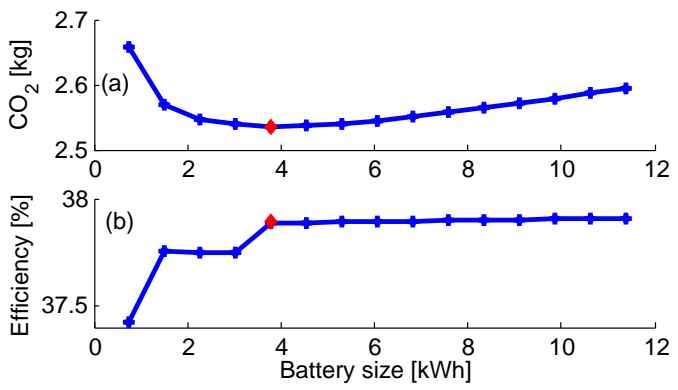

Fig. 10. Optimization results with respect to different battery sizes under the high grid $\mathrm{CO}_{2}$ level: (a) Total amount of daily $\mathrm{CO}_{2}$ emissions; (b) Average EGU efficiency.

ment when day-ahead predictions of grid $\mathrm{CO}_{2}$ is available, we consider updated control policies with fixed battery size. As illustrated in Fig. 13, the updated control policies recover nearly all of the optimality loss $(<1 \%)$, which underscores the importance of on-road power management.

\section{CONCLUSION}

This brief develops an integrated optimization framework for battery dimensioning, charging, and on-road power management of PHEVs that minimizes the total amount of daily $\mathrm{CO}_{2}$ emissions. A convex programming problem is formulated to unify the three important optimal design/control problems for systematically evaluating their interactions.

Three cases with high, medium, and low grid $\mathrm{CO}_{2}$ levels are studied for a small-size PHEV. The results reveal that as grid $\mathrm{CO}_{2}$ decreases, the PHEV increasingly depends on electricity usage, and its recharging occurs in the vicinity of lowestcarbon time. The loss of $\mathrm{CO}_{2}$ reduction caused by simulating the optimal solution in the medium $\mathrm{CO}_{2}$ case for the high $\mathrm{CO}_{2}$ case is up to approximately $14 \%$. The computational advantages of the framework permit a rapid and efficient day-ahead update of charging/power management control law, which noticeably mitigates such loss.

\section{REFERENCES}

[1] Z. Ma, D. Callaway, and I. Hiskens, "Decentralized charging control of large populations of plug-in electric vehicles," IEEE Transactions on Control Systems Technology, vol. 21, no. 1, pp. 67-78, Jan 2013.

[2] S. Moura, H. Fathy, D. Callaway, and J. Stein, "A stochastic optimal control approach for power management in plug-in hybrid electric vehicles," IEEE Transactions on Control Systems Technology, vol. 19, no. 3, pp. 545-555, May 2011.

[3] D. Callaway and I. Hiskens, "Achieving controllability of electric loads," Proceedings of the IEEE, vol. 99, no. 1, pp. 184-199, Jan 2011. 
TABLE IV

NOMENCLATURE

\begin{tabular}{|c|c|c|c|}
\hline Symbol & Description [unit] & Symbol & Description [unit] \\
\hline$a_{i}, i=0,1,2$ & Coefficients in convex electric motor model in (16) & $P_{a u}$ & Vehicular auxiliary power [W] \\
\hline$A_{f}$ & Frontal area $\left[\mathrm{m}^{2}\right]$ & $P_{b}$ & Electrochemical battery power [W] \\
\hline$A(\omega)$ & Coefficient in the torque-demand function in (15) & $P_{b t}$ & Electrical battery power $[\mathrm{W}]$ \\
\hline$b_{i}, i=0,1,2$ & Coefficients in convex engine-generator unit model in (18) & $P_{b t, \min }$ & Charging power limit while parked [W] \\
\hline$B(\omega)$ & Coefficient in the torque-demand function in (15) & $P_{\text {egu }}$ & Engine-generator unit power [W] \\
\hline$c_{c}$ & Grid-related $\mathrm{CO}_{2}[\mathrm{~kg} / \mathrm{kWh}]$ & $P_{e m}$ & Electric motor power $[\mathrm{W}]$ \\
\hline$c_{d}$ & Aerodynamic drag coefficient & $P_{\text {loss }, e m}$ & Parasitic losses in electric motor [W] \\
\hline$c_{g}$ & Gasoline-related $\mathrm{CO}_{2}[\mathrm{~kg} / \mathrm{l}]$ & $P_{\max , e g u}$ & Maximum engine-generator unit power $[\mathrm{W}]$ \\
\hline$c_{r}$ & Rolling resistance coefficient & $P_{o n}^{*}$ & Best threshold of power demand [W] \\
\hline$C$ & Equivalent Cell capacitance $[\mathrm{F}]$ & $Q$ & Nominal cell capacity $[\mathrm{As}]$ \\
\hline$e$ & Engine on/off control signal & $r$ & Wheel radius $[\mathrm{m}]$ \\
\hline$E_{b}$ & Battery energy $[\mathrm{J}]$ & $R$ & Cell resistance $[\mathrm{ohm}]$ \\
\hline$E_{\text {cell, } \min }$ & Minimum cell energy $[\mathrm{J}]$ & $s o c$ & Cell State of Charge $[\%]$ \\
\hline$E_{\text {cell, } \max }$ & Maximum cell energy $[\mathrm{J}]$ & $t_{c}$ & Charging time $[\mathrm{s}]$ \\
\hline$f(x)$ & Convex objective function in (1) & $t_{d}$ & Driving time $[\mathrm{s}]$ \\
\hline$F$ & Total amount of daily $\mathrm{CO}_{2}$ emissions to minimize $[\mathrm{kg}]$ & $T$ & Electric motor torque $[\mathrm{W}]$ \\
\hline$F_{g a s}$ & $\mathrm{CO}_{2}$ emissions related to gasoline consumption $[\mathrm{kg}]$ & $T_{\max }$ & Maximum torque of electric motor $[\mathrm{Nm}]$ \\
\hline$F_{\text {grid }}$ & $\mathrm{CO}_{2}$ emissions related to recharge $[\mathrm{kg}]$ & $T_{\min }$ & Minimum torque of electric motor $[\mathrm{Nm}]$ \\
\hline$g$ & Gravity $\left[\mathrm{m} / \mathrm{s}^{2}\right]$ & $T_{v}$ & Torque demand $[\mathrm{Nm}]$ \\
\hline$g(x)$ & Convex inequality constraint in (2) & $U(s o c)$ & Battery cell open circuit voltage [V] \\
\hline$h(x)$ & Affine equality in (3) & $U_{0}$ & Coefficient in open-circuit-voltage model (5) [V] \\
\hline$H(x)$ & Inequality constraint in Lemma 1 & $v$ & Vehicle velocity $[\mathrm{m} / \mathrm{s}]$ \\
\hline$i$ & Cell current $[\mathrm{A}]$ & $x$ & Optimization variable \\
\hline$i_{\max }$ & Maximum Cell discharge current $[\mathrm{A}]$ & $\beta$ & Road slope [rad] \\
\hline$i_{\text {min }}$ & Maximum Cell charge current $[\mathrm{A}]$ & $\rho$ & Air density $\left[\mathrm{kg} / \mathrm{m}^{3}\right]$ \\
\hline$I$ & Inertia of final drive and wheels $\left[\mathrm{kgm}^{2}\right]$ & $\rho_{g}$ & Gasoline density $[\mathrm{g} / \mathrm{l}]$ \\
\hline$I_{e m}$ & Electric motor inertia $\left[\mathrm{kgm}^{2}\right]$ & $\Delta t$ & Time interval $[\mathrm{s}]$ \\
\hline$k$ & Time index & $\Delta t_{c}$ & Time interval during charging $[\mathrm{s}]$ \\
\hline$L_{g}$ & Gasoline lower heating value $[\mathrm{J} / \mathrm{g}]$ & $\Delta t_{d}$ & Time interval during driving $[\mathrm{s}]$ \\
\hline$m_{b}$ & Cell mass $[\mathrm{kg}]$ & $\nabla^{2}$ & Hessian operator \\
\hline$m_{v}$ & Vehicle mass excluding battery pack $[\mathrm{kg}]$ & $\lambda$ & Final gear \\
\hline$M_{c}$ & Time set for charging & $\omega$ & Electric motor angular speed $[\mathrm{rad} / \mathrm{s}]$ \\
\hline$M_{d}$ & Time set for driving & $\eta_{c}$ & Average charger efficiency [\%] \\
\hline$n$ & Number of battery cells & & \\
\hline
\end{tabular}

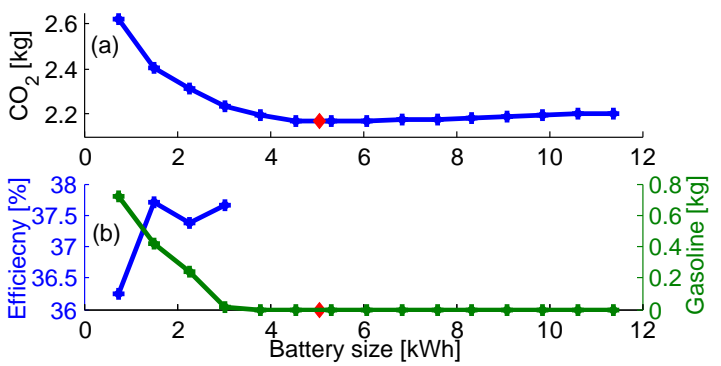

Fig. 11. Optimization results with respect to different battery sizes under the low grid $\mathrm{CO}_{2}$ level: (a) Total amount of daily $\mathrm{CO}_{2}$ emissions, (b) Average EGU efficiency and gasoline consumption.

[4] K. Clement-Nyns, E. Haesen, and J. Driesen, "The impact of charging plug-in hybrid electric vehicles on a residential distribution grid," IEEE Transactions on Power Systems, vol. 25, no. 1, pp. 371-380, Feb 2010.

[5] Z. Ma, S. Zou, and X. Liu, "A distributed charging coordination for large-scale plug-in electric vehicles considering battery degradation cost," IEEE Transactions on Control Systems Technology, vol. PP, no. 99 , pp. 1-1, 2015.

[6] Y. He, B. Venkatesh, and L. Guan, "Optimal scheduling for charging and discharging of electric vehicles," IEEE Transactions on Smart Grid, vol. 3, no. 3, pp. 1095-1105, Sept 2012.

[7] N. Rotering and M. Ilic, "Optimal charge control of plug-in hybrid electric vehicles in deregulated electricity markets," IEEE Transactions on Power Systems, vol. 26, no. 3, pp. 1021-1029, Aug 2011.

[8] C. Ahn, C.-T. Li, and H. Peng, "Optimal decentralized charging control algorithm for electrified vehicles connected to smart grid," Journal of Power Sources, vol. 196, no. 23, pp. 10369 - 10379, 2011.

[9] W. Tushar, W. Saad, H. Poor, and D. Smith, "Economics of electric vehicle charging: A game theoretic approach," IEEE Transactions on Smart Grid, vol. 3, no. 4, pp. 1767-1778, Dec 2012.

[10] R. Patil, Z. Filipi, and H. Fathy, "Comparison of supervisory control strategies for series plug-in hybrid electric vehicle powertrains through dynamic programming," IEEE Transactions on Control Systems Technology, vol. 22, no. 2, pp. 502-509, March 2014.

[11] P. Pisu and G. Rizzoni, "A comparative study of supervisory control strategies for hybrid electric vehicles," IEEE Transactions on Control Systems Technology, vol. 15, no. 3, pp. 506-518, May 2007.

[12] P. Tulpule, V. Marano, and G. Rizzoni, "Energy management for plugin hybrid electric vehicles using equivalent consumption minimisation strategy," International Journal of Electric and Hybrid Vehicles, vol. 2, no. 4, pp. 329-350, Jan 2010.

[13] S. Stockar, V. Marano, M. Canova, G. Rizzoni, and L. Guzzella, "Energy-optimal control of plug-in hybrid electric vehicles for realworld driving cycles," IEEE Transactions on Vehicular Technology, 

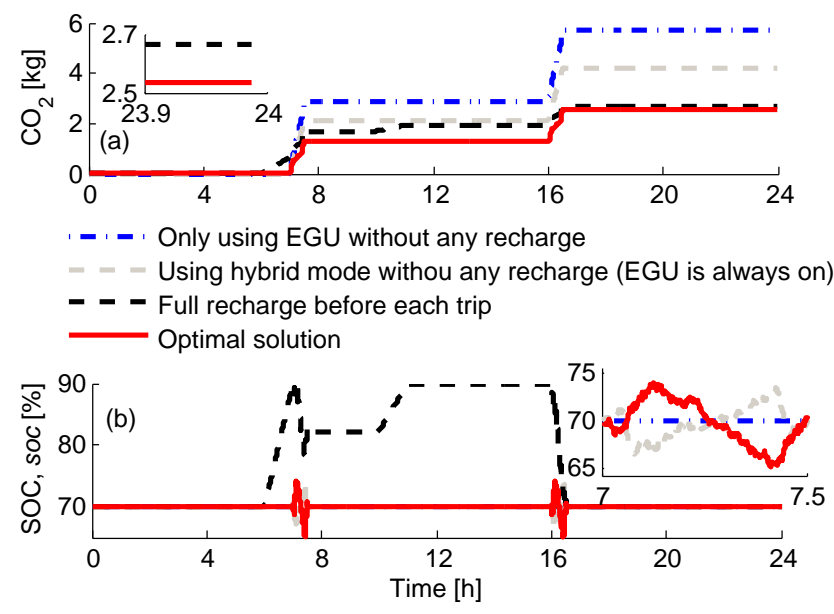

Fig. 12. Comparison of different charging/power management strategies with the optimal battery size (shown in Table III) under the high grid $\mathrm{CO}_{2}$ level: (a) Cumulative $\mathrm{CO}_{2}$; (b) 24-hour SOC trajectory.

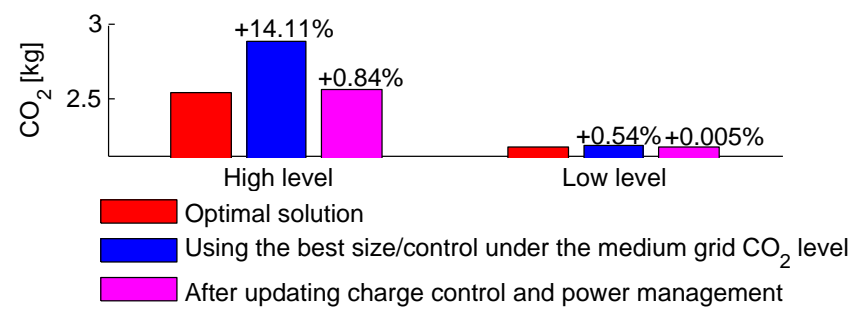

Fig. 13. Comparison of the total amount of daily $\mathrm{CO}_{2}$ emissions (optimality loss of $\mathrm{CO}_{2}$ reduction).

vol. 60, no. 7, pp. 2949-2962, Sept 2011.

[14] N. Kim, S. Cha, and H. Peng, "Optimal control of hybrid electric vehicles based on pontryagin's minimum principle," IEEE Transactions on Control Systems Technology, vol. 19, no. 5, pp. 1279-1287, Sept 2011.

[15] H. Borhan, A. Vahidi, A. Phillips, M. Kuang, I. Kolmanovsky, and S. Di Cairano, "Mpc-based energy management of a power-split hybrid electric vehicle," IEEE Transactions on Control Systems Technology, vol. 20, no. 3, pp. 593-603, May 2012.

[16] S. Di Cairano, D. Bernardini, A. Bemporad, and I. Kolmanovsky, "Stochastic mpc with learning for driver-predictive vehicle control and its application to hev energy management," IEEE Transactions on Control Systems Technology, vol. 22, no. 3, pp. 1018-1031, May 2014.

[17] X. Hu, N. Murgovski, L. Johannesson, and B. Egardt, "Comparison of three electrochemical energy buffers applied to a hybrid bus powertrain with simultaneous optimal sizing and energy management," IEEE Transactions on Intelligent Transportation Systems, vol. 15, no. 3, pp. 1193-1205, June 2014

[18] Y. Ota, H. Taniguchi, T. Nakajima, K. Liyanage, and A. Yokoyama, "An autonomous distributed vehicle-to-grid control of grid-connected electric vehicle," in 2009 International Conference on Industrial and Information Systems (ICIIS), Dec 2009, pp. 414-418.

[19] R. Patil, J. Kelly, Z. Filipi, and H. Fathy, "A framework for the integrated optimization of charging and power management in plug-in hybrid electric vehicles," IEEE Transactions on Vehicular Technology, vol. 62 , no. 6, pp. 2402-2412, July 2013.

[20] S. Bashash and H. Fathy, "Optimizing demand response of plug-in hybrid electric vehicles using quadratic programming," in American Control Conference (ACC), 2013, June 2013, pp. 716-721.

[21] E. Tazelaar, Y. Shen, P. Veenhuizen, T. Hofman, and P. van den Bosch, "Sizing stack and battery of a fuel cell hybrid distribution truck," Oil Gas Sci. Technol., vol. 67, no. 4, pp. 563-573, 2012.

[22] A. Ravey, R. Roche, B. Blunier, and A. Miraoui, "Combined optimal sizing and energy management of hybrid electric vehicles," in Transportation Electrification Conference and Expo (ITEC), 2012 IEEE, June 2012, pp. 1-6.

[23] S. Ebbesen, C. Donitz, and L. Guzzella, "Particle swarm optimisation for hybrid electric drive-train sizing," International Journal of Vehicle Design, vol. 58, no. 2, pp. 181-199, June 2012.

[24] C. Mi, M. Abul Masrur, and W. Gao, Hybrid Electric Vehicles: Principles and Applications with Practical Perspectives. Wiley, 2011.

[25] E. Silvas, T. Hofman, and M. Steinbuch, "Review of optimal design strategies for hybrid electric vehicles," in 2012 Workshop on Engine and Powertrain Control, Simulation and Modeling, The International Federation of Automatic Control, October 2012, pp. 57-64.

[26] S. Boyd and L. Vandenberghe, Convex optimization. Cambridge university press, 2009.

[27] B. Egardt, N. Murgovski, M. Pourabdollah, and L. Johannesson Mardh, "Electromobility studies based on convex optimization: Design and control issues regarding vehicle electrification," IEEE Control Systems Magazine, vol. 34, no. 2, pp. 32-49, April 2014.

[28] G. A. Keoleian, J. C. Kelly, J. MacDonald, A. Camere, C. de Monasterio, and A. Schafer, "Environmental assessment of plug-in hybrid electric vehicles in michigan: greenhouse gas emissions, criteria air pollutants, and petroleum displacement," University of Michigan, Ann Arbor, MI, USA, Tech. Rep., 2011.

[29] H. Yu, M. Kuang, and R. McGee, "Trip-oriented energy management control strategy for plug-in hybrid electric vehicles," IEEE Transactions on Control Systems Technology, vol. 22, no. 4, pp. 1323-1336, July 2014.

[30] C. Zhang and A. Vahidi, "Route preview in energy management of plugin hybrid vehicles," IEEE Transactions on Control Systems Technology, vol. 20, no. 2, pp. 546-553, March 2012.

[31] Y. Labit, D. Peaucelle, and D. Henrion, "Sedumi interface 1.02: a tool for solving lmi problems with sedumi," in 2002 IEEE International Symposium on Computer Aided Control System Design, 2002. Proceedings, Sept 2002, pp. 272-277.

\section{APPENDIX}

Given the bus velocity $v$ and the road slope $\beta$, the angular speed $\omega$ and the torque demand $T_{v}$ on the shaft between the EM and the final drive are determined by

$$
\begin{aligned}
\omega= & \frac{\lambda v}{r}, \\
T_{v}= & \frac{g r}{\lambda}\left(m_{v}+1.123 m_{b} n\right)\left(c_{r} \cos \beta+\sin \beta\right)+\frac{\rho A_{f} c_{d} r^{3} \omega^{2}}{2 \lambda^{3}} \\
& +\left(I_{e m}+\frac{I+\left(m_{v}+1.123 m_{b} n\right) r^{2}}{\lambda^{2}}\right) \frac{d \omega}{d t}, \\
= & A(\omega) n+B(\omega),
\end{aligned}
$$

for appropriately defined coefficients $A(\omega), B(\omega)$, where the parameters are defined in Table I and Table II. 